\title{
Criptógamos do Parque Estadual das Fontes do Ipiranga, São Paulo, SP. Fungos, 9: Meripilaceae
}

\author{
Giuliana Ribeiro Leal ${ }^{1}$ e Adriana de Mello Gugliotta ${ }^{1,2}$
}

Recebido: 11.10.2007; aceito: 20.03.2008

ABSTRACT - (Cryptogams of the "Parque Estadual das Fontes do Ipiranga", São Paulo, SP. Fungi, 9: Meripilaceae). A survey of Meripilaceae species from "Parque Estadual das Fontes do Ipiranga", Municipality of São Paulo, São Paulo State, Brazil was carried out. Six species were identified: Abortiporus fractipes (Berk. \& M.A. Curtis) Gilbn. \& Ryvarden, Antrodia albida (Fr.) Donk, Hydnopolyporus fimbriatus (Fr.) D.A. Reid, Rigidoporus lineatus (Pers.) Ryvarden, R. microporus (Sw.) Overeem and R. vinctus (Berk.) Ryvarden. Antrodia albida is new record for São Paulo State. Identification key, descriptions, comments and illustrations of the taxa studied are provided herewith.

Key words: Atlantic Forest, Basidiomycota, biodiversity, taxonomy

RESUMO - (Criptógamos do Parque Estadual das Fontes do Ipiranga, São Paulo, SP. Fungos, 9: Meripilaceae). Foi realizado levantamento das espécies de Meripilaceae que ocorrem no Parque Estadual das Fontes do Ipiranga (PEFI), Município de São Paulo, Estado de São Paulo, Brasil. Foram identificadas seis espécies: Abortiporus fractipes (Berk. \& M.A. Curtis) Gilbn. \& Ryvarden, Antrodia albida (Fr.) Donk, Hydnopolyporus fimbriatus (Fr.) D.A. Reid, Rigidoporus lineatus (Pers.) Ryvarden, R. microporus (Sw.) Overeem e R. vinctus (Berk.) Ryvarden. Antrodia albida é nova citação para o Estado de São Paulo. São apresentados chave de identificação, descrição, ilustração e comentários para cada táxon estudado.

Palavras-chave: Basidiomycota, biodiversidade, Mata Atlântica, taxonomia

\section{Introdução}

A família Meripilaceae Jülich (Polyporales) engloba fungos macroscópicos, lignícolas, poliporóides, de ampla distribuição nos biomas terrestres onde possuem papel fundamental na degradação da celulose e lignina (Rayner 1995). Abrange fungos lignícolas, com basidiomas crescendo sobre madeira, ou em solo associados à decomposição de raízes e madeira enterrada, o que ocorre em representantes de Abortiporus, Diachanthodes e Meripilus. Antrodia é o único gênero da família que causa podridão parda, os demais são causadores de podridão branca (Gilbertson \& Ryvarden 1986, 1987, Ryvarden 1991).

Segundo Kirk et al. (2001), esta família possui nove gêneros: Abortiporus Murrill, Antrodia P. Karst., Diachanthodes Singer, Grifola Gray, Henningsia Möller, Hydnopolyporus D.A. Reid, Meripilus Karst., Physisporinus Karst. e Rigidoporus Murrill. Seus representantes são, na maioria, anuais, poucos são perenes, apresentam basidioma ressupinado a estipitado, sistema hifálico monomítico a dimítico com hifas esqueléticas, hifas generativas com ansas ou septos simples e basidiósporos de parede lisa, cilíndricos, oblongo-elipsóides a globosos; algumas espécies ainda podem apresentar cistídios com parede lisa ou incrustrada (Gilbertson \& Ryvarden 1986, 1987, Ryvarden 1991).

Os representantes desta família apresentam ampla distribuição geográfica. Os gêneros mais representativos são Antrodia e Rigidoporus que possuem 36 e 30 espécies respectivamente. Diacanthodes e Henningsia são gêneros monotípicos, sendo que $D$. novoguineensis (Henn.) O. Fidalgo possui distribuição pantropical, enquanto $H$. brasiliensis (Speg.) Speg. ocorre apenas na região neotropical (Kirk et al. 2001). Os demais gêneros possuem poucas espécies descritas até o momento: Grifola e Meripilus estão representados por cinco espécies cada; Abortiporus com quatro espécies, Hydnopolyporus com três espécies e Physisporinus com duas espécies (Kirk et al. 2001).

Com exceção de Grifola, que apresenta distribuição restrita às regiões temperadas, os demais gêneros estão bem representados nos trópicos, ocorrendo em diversos ecossistemas brasileiros (Fidalgo \& Fidalgo 1957, Fidalgo et al. 1965, Bononi 1984, Capelari \& Maziero

1. Instituto de Botânica, Caixa Postal 3005, 01061-970 São Paulo, SP, Brasil

2. Autor para correspondência: agugliottaibot@yahoo.com.br 
1988, Silveira \& Guerrero 1989, 1991, Rajchenberg \& Meijer 1990, Loguercio-Leite \& Wright 1991, Sotão et al. 1991, 2003, Almeida Filho et al. 1993, Jesus 1996, Gugliotta 1997, Góes Neto 1999, Gugliotta \& Bononi 1999, Gerber \& Loguercio-Leite 2000, Gonçalves \& Loguercio-Leite 2001, Maia et al. 2002, Ryvarden \& Meijer 2002, Gibertoni \& Cavalcanti 2003, Góes Neto et al. 2003, Gibertoni et al. 2004, Meijer 2006).

Entre os trabalhos publicados sobre a diversidade do Parque Estadual das Fontes do Ipiranga (PEFI), poucos são os que tratam da família Meripilaceae, evidenciando um conhecimento muito restrito deste grupo de fungos na área. Os únicos estudos sobre esta família foram realizados por Bononi et al. (1981) que publicaram uma listagem das espécies de fungos macroscópicos depositados no Herbário do Instituto de Botânica (SP), sem qualquer descrição ou ilustração das espécies, e por Jesus (1993) que apresentou uma comparação dos basidiomicetos lignocelulolíticos de uma área de floresta nativa e de uma floresta de Pinus elliottii, presentes no interior do PEFI.

Bononi et al. (1981) relacionaram as seguintes espécies de Meripilaceae: Fomes geotropus (Cooke) Cooke, F. microporus (Sw.) Fr., F. ulmarius Fr., Heteroporus fractipes (Berk. \& M.A. Curtis) O. Fidalgo, Hydnopolyporus fimbriatus (Fr.) D.A. Reid, Rigidoporus liebmannii (Fr.) Murrill, R. lignosus (Klotzsch) Imazeki e R. microporus (Sw.) Overeem, além de sete exsicatas identificadas em nível genérico, incluídas em Coriolellus Murrill (sinônimo de Antrodia) e Rigidoporus. Neste trabalho não são fornecidas descrições das espécies.

Atualmente, Fomes geotropus e F. ulmarius são considerados sinônimos de Rigidoporus ulmarius (Sowerby) Imazeki; F. microporus e R. lignosus são sinônimos de Rigidoporus microporus e Heteroporus fractipes de Abortiporus fractipes. Rigidoporus liebmannii Fr. citado por Bononi et al. (1981) corresponde à espécie Flaviporus liebmanni (Fr.) Ginns, atualmente incluída em Steccherinaceae (Kirk et al. 2001). Bononi et al. (1981) citaram, também, a ocorrência de uma exsicata identificada como cf. Poria vitrea Pers., espécie atualmente incluída no gênero Physisporinus [P. vitreus (Pers.) P. Karst.].

Jesus (1993) relacionou três táxons de Meripilaceae: Rigidoporus lineatus, $R$. microporus e $R$. vinctus. Este trabalho, no entanto, não possui enfoque taxonômico, apresentando apenas uma listagem dos táxons encontrados, não sendo mencionados dados morfológicos nem o número de inclusão no Herbário SP.

Devido à escassez de estudos sobre Meripilaceae no PEFI; objetivamos ampliar o conhecimento sobre a diversidade desse grupo na área. Este trabalho faz parte de um amplo projeto de levantamento de fungos basidiomicetos do Parque Estadual das Fontes do Ipiranga.

\section{Material e métodos}

O Parque Estadual das Fontes do Ipiranga (PEFI) situa-se no município de São Paulo ( $23^{\circ} 38^{\prime} 00^{\prime}$ 'S -

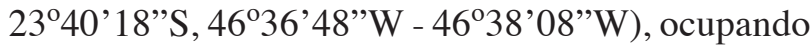
uma área de 549,31 ha com altitude média de $798 \mathrm{~m}$. A vegetação é caracterizada como floresta ombrófila densa e representa um dos mais significativos remanescentes de mata inserido em área urbana do município. Aspectos climáticos, do meio físico e da vegetação podem ser encontrados em Bicudo et al. (2002).

Foram realizadas coletas bimensais no período de abril de 2000 a março de 2001, setembro de 2003 a fevereiro de 2005, além de coletas esporádicas de março de 2005 a março de 2007. A coleta seguiu as recomendações de Fidalgo \& Bononi (1984). Também foram revistas as exsicatas depositadas no Herbário SP provenientes de coletas anteriores.

Caracteres macro e microscópicos do basidioma foram analisados para identificação, seguindo Fidalgo (1968), Ryvarden (1991) e Teixeira (1995) e as microestruturas foram analisadas segundo as recomendações de Teixeira $(1962,1995)$. As reações amilóide e dextrinóide foram testadas com reagente de Melzer (Gilbertson \& Ryvarden 1986, Teixeira 1995). Todo material coletado encontra-se depositado no Herbário SP.

A classificação segundo Kirk et al. (2001), pode ser consultada nas bases de dados CABI (http://www. indexfungorum.org) e CBS (http://www.cbs.knaw.nl).

São apresentados descrição, comentários e ilustrações dos táxons estudados, além de uma chave de identificação para as espécies presentes no PEFI.

\section{Resultados e Discussão}

A família está representada no Parque por seis espécies: Abortiporus fractipes (Berk. \& M.A. Curtis) Gilbn. \& Ryvarden, Antrodia albida (Fr.) Donk, Hydnopolyporus fimbriatus (Fr.) D.A. Reid, Rigidoporus lineatus (Pers.) Ryvarden, $R$. microporus (Sw.) Overeem e $R$. vinctus (Berk.) Ryvarden. Antrodia albida é nova citação para o Estado de São Paulo. 
A análise do espécime citado por Bononi et al. (1981) como cf. Poria vitrea Pers, espécie atualmente incluída em Physisporinus, revelou a presença de ansas nas hifas generativas, as quais estão ausentes neste gênero. Assim, não foi constatada a ocorrência deste táxon no PEFI.
A ocorrência de Rigidoporus ulmarius citada por Bononi et al. (1981) como Fomes geotropus (SP1447) e Fomes ulmarius (SP39617) não foi confirmada: o material SP1447 não foi localizado, enquanto que a exsicata SP39617 não representa uma espécie de Polyporales.

Chave de identificação para as espécies de Meripilaceae que ocorrem no PEFI

1. Basidioma sempre cespitoso, com numerosos píleos unidos formando rosetas ..... Hydnopolyporus fimbriatus

1. Basidioma ressupinado a pileado, nunca em forma de roseta

2. Basidioma pileado

3. Basidioma estipitado; hifas generativas com ansas

3. Basidioma séssil, efuso-reflexo a pileado; hifas generativas com septos simples

4. Cistídios presentes Abortiporus fractipes

4. Cistídios ausentes Rigidoporus lineatus

2. Basidioma ressupinado Rigidoporus microporus

5. Sistema hifálico dimítico; hifas generativas com ansas; basidiósporos cilíndricos ... Antrodia albida

5. Sistema hifálico monomítico; hifas generativas com septos simples; basidiósporos globosos

6. Basidioma anual; superfície himenial castanho-rosada, não se alterando após a desidratação Rigidoporus vinctus var. vinctus

6. Basidioma perene; superfície himenial castanho-rosada quando fresca, tornando-se castanho-acinzentada quando seca Rigidoporus vinctus var. cinereus

Abortiporus Murrill, Bull. Torrey bot. Club 31: 421. 1904.

Basidioma anual, estipitado, infundibuliforme a séssil e dimidiado. Superfície himenial poróide, poros angulares a dedalóides. Contexto dúplex, branco a castanho-claro, a parte superior macia, esponjosa, a parte inferior firme, fibrosa. Sistema hifálico monomítico; hifas generativas não amilóides e não dextrinóides; com ansas. Cistídios presentes ou ausentes. Clamidósporos presentes na parte superior do contexto. Basidiósporos subglobosos a elipsóides, hialinos, não amilóides e não dextrinóides, parede lisa e levemente espessada.

Abortiporus apresenta distribuição cosmopolita e abrange espécies lignícolas causadoras de podridão branca, geralmente associadas à decomposição de raízes e madeira enterrada (Gilbertson \& Ryvarden 1986). No presente trabalho, apenas Abortiporus fractipes (Batsch) Fr.foi encontrado.

Abortiporus fractipes (Berk. \& M.A. Curtis) Gilbn. \& Ryvarden, N. Amer. Polyp. 1: 85. $1986 \equiv$ Polyporus fractipes Berk. \& M.A. Curtis, Grevillea 1:39. 1872 = Heteroporus fractipes (Berk. \& M.A. Curtis) O. Fidalgo. Rickia 4: 149. 1969.

Figuras 1-3
Basidioma anual, estipitado, solitário. Píleo flabeliforme, carnoso quando fresco, tornando-se rígido quando seco, $4 \times 2,5 \mathrm{~cm}$, até $0,2 \mathrm{~cm}$ espesso na base. Superfície superior ocrácea, estriada quando seca, vilosa, tornando-se glabra na maturidade. Margem concolor à superfície superior a levemente mais escura, inteira, involuta quando seca. Estipe lateral, cilíndrico, glabro, concolor à superfície superior, 2,3 $\times 0,4-0,5 \mathrm{~cm}$. Superfície himenial poróide, ocrácea, mais clara que a superfície superior, poros regulares, angulares, $10-12 / \mathrm{mm}$; tubos concolores à superfície himenial, até $0,1 \mathrm{~cm}$ compr.; dissepimentos levemente fimbriados. Contexto dúplex, a parte superior flocosa, concolor à superfície superior, a parte inferior mais densa e levemente mais escura, até $0,1 \mathrm{~cm}$ espesso. Sistema hifálico monomítico; hifas generativas não amilóides e não dextrinóides, com ansas, hialinas, 2,5-5 $\mu \mathrm{m}$ diâm., na parte superior do contexto mais frouxamente arranjadas, parede fina a espessa, com poucas ramificações, na parte inferior do contexto com parede espessa, não ramificadas, com poucas ansas, lembrando hifas esqueléticas. Clamidósporos raros, presentes no contexto, hialinos, parede espessa, subglobosos, 5-7 $\mu \mathrm{m}$ diâm. Cistídios ausentes. Basídios não observados. Basidiósporos hialinos, não 
amilóides e não dextrinóides, elipsóides a subglobosos, com parede fina e lisa, 5-6,25 × 3,75-5 $\mu \mathrm{m}$.

Material examinado: BRASIL. SÃo PAULO: São Paulo, Parque Estadual das Fontes do Ipiranga, 24-V-1969, B. Skvortzov s.n. (SP103956).

A espécie ocorre com maior freqüência no Continente Americano, tendo registros para Estados Unidos da América, Jamaica, México (Fidalgo 1969, Gilbertson \& Ryvarden 1986), raramente na Europa (Ryvarden \& Gilbertson 1993). No Brasil foi citada para os Estados do Amazonas, Bahia, Rio Grande do Sul, Santa Catarina e São Paulo (Fidalgo \& Fidalgo 1957, Fidalgo 1969); sua ocorrência no Parque já havia sido relatada por Bononi et al. (1981, como Heteroporus fractipes).

O espécime examinado não apresenta informação quanto ao habitat; porém, a espécie normalmente cresce em madeira enterrada e raízes, causando podridão branca (Fidalgo 1969). Para a sinonímia consultar Fidalgo (1969) e Gilbertson \& Ryvarden (1986).

Antrodia P. Karst., Meddn Soc. Fauna Flora fenn. 5: 40.1879.

Basidioma anual a perene, ressupinado a efusoreflexo, raramente pileado séssil, a maioria de coloração clara. Superfície himenial poróide. Sistema hifálico dimítico; hifas generativas não amilóides e não dextrinóides; com ansas; hifas esqueléticas presentes, hialinas ou levemente coloridas em poucas espécies, geralmente não amilóides, variavelmente amilóides em poucas espécies. Cistídios ausentes; cistidíolos geralmente presentes entre os basídios, pequenos, ventricosos e agudos. Basidiósporos cilíndricos a oblongo-elipsóides, hialinos, não amilóides e não dextrinóides, parede lisa e fina.

Antrodia é gênero de distribuição cosmopolita (Gilbertson \& Ryvarden 1986), abrange espécies lignícolas e causadoras de podridão parda. No presente trabalho, apenas Antrodia albida (Fr.) Donk foi encontrada.

Antrodia albida (Fr.) Donk, Persoonia 4: 339. $1966 \equiv$

Daedalea albida Fr., Observ. mycol. 1: 107. 1815. Figuras 4-6

Basidioma lignícola, anual, ressupinado, rígido, muito aderido ao substrato, cobrindo pequenas áreas, 0,5-3 $\times 0,5-4,5 \mathrm{~cm}$, muito fino, menos de $0,1 \mathrm{~cm}$ espesso. Superfície himenial poróide, branca a creme, escurecendo levemente quando seca; poros variáveis, angulares a alongados, $1-3 / \mathrm{mm}$; tubos concolores, rasos, menos de $0,1 \mathrm{~cm}$ compr. Margem estéril, concolor à superfície, felpada. Contexto homogêneo, concolor à superfície, muito fino. Sistema hifálico dimítico; hifas não amilóides e não dextrinóides; hifas generativas hialinas, com ansas, ramificadas, parede fina a espessa, 2,5-3,75 $\mu \mathrm{m}$ diâm.; hifas esqueléticas hialinas, não ramificadas ou raramente com ramificações dicotômicas, parede espessa a quase sólida, 2,5-5 $\mu \mathrm{m}$ diâm. Cistídios ausentes. Basídios não observados. Basidiósporos cilíndricos, hialinos, não amilóides e não dextrinóides, parede fina e lisa, $12,5-15 \times 3,75-6,25 \mu \mathrm{m}$.

Material examinado: BRASIL. SÃo PAULO: São Paulo, Parque Estadual das Fontes do Ipiranga, 21-III-1969, B. Skvortzov s.n. (SP103776); 6-XI-2003, M. Capelari et al. s.n. (SP 392799).

$\mathrm{O}$ basidioma ressupinado, muito fino, com poros grandes $(1-3 / \mathrm{mm})$ e basidiósporos cilíndricos e grandes são boas características para o reconhecimento desta espécie.

Embora os exemplares do PEFI apresentem basidioma exclusivamente ressupinado, a espécie pode apresentar basidioma ressupinado a efusoreflexo com numerosos píleos estreitos, imbricados, com a superfície poróide decurrente e, neste caso, a superfície superior é branca a creme, inicialmente finamente tomentosa, tornando-se glabra na maturidade (Ryvarden \& Johansen 1980). Espécie de distribuição cosmopolita (Ryvarden \& Johansen 1980), no Brasil foi citada para os Estados do Paraná (Ryvarden \& Meijer 2002, Meijer 2006), Pernambuco (Maia et al. 2002) e Santa Catarina (Loguercio-Leite \& Wright 1991). Bononi et al. (1981) haviam relacionado a exsicata SP103776 como Coriollelus sp., que no presente trabalho confirmamos tratar-se de Antrodia albida. Trata-se da primeira referência da espécie para o Estado de São Paulo.

Hydnopolyporus D.A. Reid, Persoonia 2: 151. 1962.

Basidioma anual, séssil, solitário a cespitoso, geralmente composto de numerosos píleos flabeliformes, irregulares, formando pequenas rosetas; quando solitário constituído de grande número de segmentos estreitos, aplanados, em forma de tiras, unidas na base. Superfície superior branca a pálida, mais escura quando seca, finamente velutina a glabra, estriada, azonada a zonada. Superfície himenial quase lisa, papilosa, hidnóide a irregularmente poróide, branca, poros angulares. Contexto homogêneo, branco. Sistema hifálico monomítico; hifas generativas 


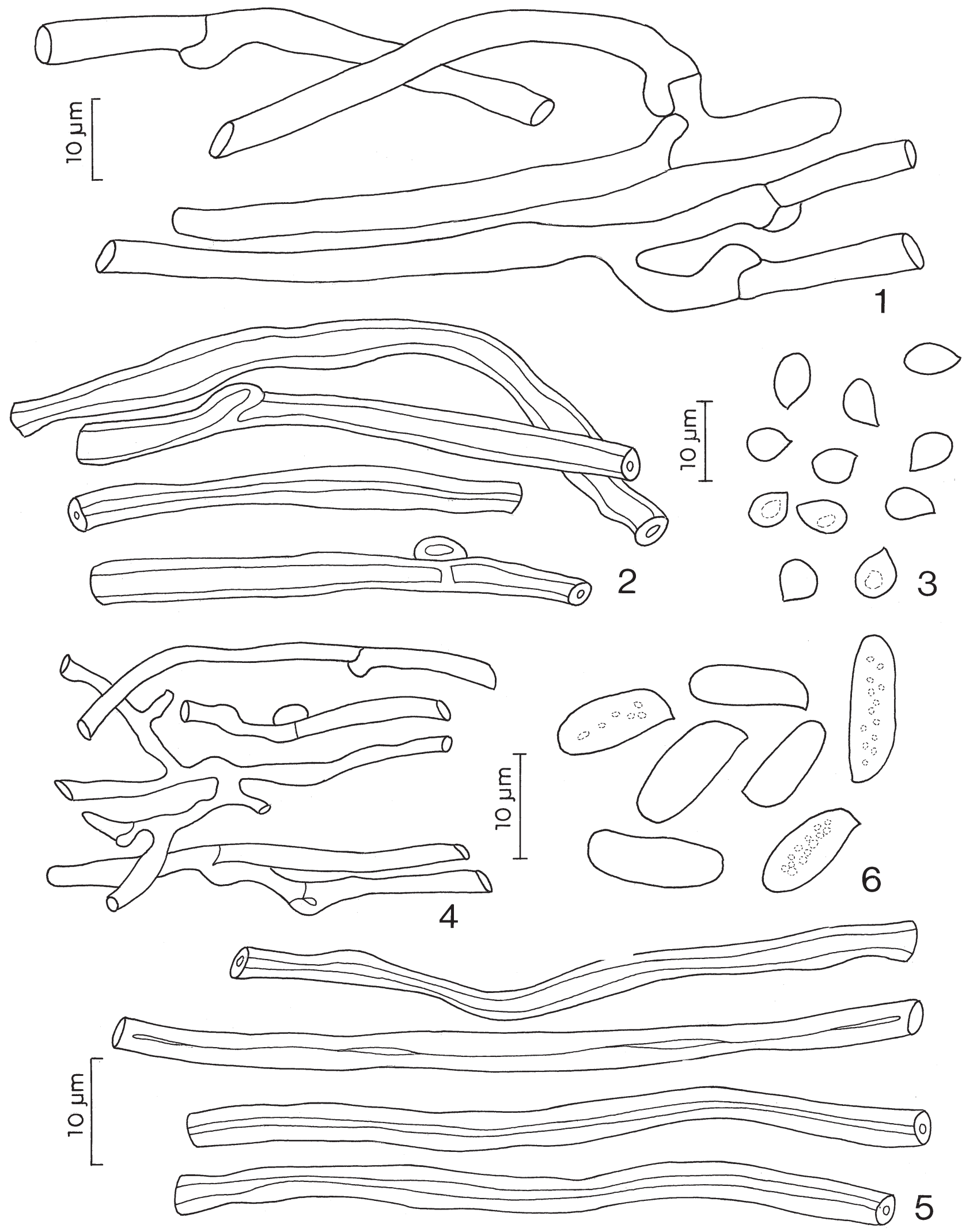

Figuras 1-3. Abortiporus fractipes. 1. Hifas generativas da parte superior do contexto. 2. Hifas generativas da parte inferior do contexto. 3. Basidiósporos. Figuras 4-6. Antrodia albida. 4. Hifas generativas. 5. Hifas esqueléticas. 6. Basidiósporos. 
não amilóides e não dextrinóides; hialinas, septos simples, ramificadas, estreitas a largas, até $10 \mu \mathrm{m}$ diâm. Cistídios ausentes. Basidiósporos largamente elipsóides a ovóides, hialinos, não amilóides e não dextrinóides, parede fina, pequenos.

Hydnopolyporus é caracterizado pelo basidioma irregular, em forma de roseta, com superfície himenial variável, desde quase lisa até irregularmente poróide. $\mathrm{O}$ gênero ocorre no Continente Americano e inclui fungos lignícolas e causadores de podridão branca (Gilbertson \& Ryvarden 1986). No presente trabalho, apenas Hydnopolyporus fimbriatus (Fr.) D.A. Reid foi encontrado.

Hydnopolyporus fimbriatus (Fr.) D.A. Reid, Persoonia 2: 151. 1962 ㅇolyporus fimbriatus Fr., Syst. Mycol. 1: 506. 1821 Polystictus fimbriatus (Fr.) Cooke, Grevillea 14: 81. 1886. Figuras 7-8

Basidioma lignícola, anual, séssil a subestipitado, cespitoso, formando numerosas rosetas. Píleo flabeliforme a espatulado, muito dividido em lobos planos unidos pela base, 1,3-2,9 × 0,6-1,4 cm, 0,1-0,2 cm espesso. Superfície superior creme-clara a castanho-clara, glabra, radialmente estriada. Margem aguda, castanho-escura, fimbriada, involuta quando seca. Superfície himenial creme-clara, papilosa a hidnóide, 1-3 dentes $/ \mathrm{mm}$. Contexto homogêneo, branco a bege, menor que $0,1 \mathrm{~cm}$ espesso. Sistema hifálico monomítico; hifas generativas hialinas, não amilóides e não dextrinóides, com septo simples, ramificadas, parede fina a ligeiramente espessada, 2,5-8,75 $\mu \mathrm{m}$ diâm. Cistídios ausentes. Basídios não observados. Basidiósporos subglobosos, hialinos, não amilóides e não dextrinóides, parede fina e lisa, $3,75-6,25 \times 2,5 \mu \mathrm{m}$.

Material examinado: BRASIL. São Paulo: São Paulo, Parque Estadual das Fontes do Ipiranga, 1-II-1960, O. Fidalgo et al. s.n. (SP46786); 6-II-1960, O. Fidalgo et al. s.n. (SP46666); 8-II-1960, O. Fidalgo et al. s.n. (SP46963); 11-II-1960, O. Fidalgo et al. s.n. (SP49392); 3-III-1960, O. Fidalgo et al. s.n. (SP47638); 24-III-1961, O. Fidalgo et al. s.n. (SP60385); 19-IV-1962, A.R. Salles s.n. (SP61183; SP61185; SP61224; SP94925); 28-I-1964, $B$. Skvortzov s.n. (SP95020); 6-I-1966, M.C. Marino s.n. (SP83972); 20-II-1968, A.I. Milanez s.n. (SP102102); 15-I-1969, B. Skvortzov s.n. (SP103702); 14-I-1970, B. Skvortzov s.n. (SP107431); 12-IV-1978, S.F.B. Truffem s.n. (SP141944); 25-II-1981, M.M.
Babogh s.n. (SP157188); 12-I-1982, M. Capelari s.n. (SP157568); 24-II-1983, L.M.M. Batista s.n. (SP178226); 19-III-2003, A.M. Gugliotta \& M. Capelari 1182 (SP); 8-IV-2004, A.M. Gugliotta \& M. Capelari 1212 (SP).

O basidioma em forma de roseta e a superfície himenial variável, papilosa a hidnóide, o sistema hifálico monomítico, com hifas generativas sem ansas e os basidiósporos subglobosos são boas características para o reconhecimento da espécie.

Hydnopolyporus fimbriatus é espécie comum nas áreas tropicais do Continente Americano (Reid 1962, Fidalgo 1963, como Hydnopolyporus palmatus (Hook.) O. Fidalgo, Gilbertson \& Ryvarden 1986) e no Brasil, foi citado para os Estados do Amazonas, Bahia, Mato Grosso, Paraná, Rio de Janeiro, Rio Grande do Sul, Rondônia, Santa Catarina e São Paulo (Fidalgo \& Fidalgo 1957, Rick 1960, como Polystictus fimbriatus, Fidalgo 1963, como $H$. palmatus, Fidalgo et al. 1965, como H. palmatus, Bononi 1979, 1984, Guerrero \& Homrich 1983, Capelari \& Maziero 1988, Gugliotta \& Bononi 1999, Gerber \& Loguercio-Leite 2000, Ryvarden \& Meijer 2002, Meijer 2006). Sua ocorrência no Parque foi relatada por Bononi et al. (1981). Para a sinonímia consultar Fidalgo (1963).

Rigidoporus Murrill, Bull. Torrey bot. Club 32: 478. 1905.

Basidioma anual a perene, ressupinado a pileado. Píleo séssil dimidiado a circular. Superfície superior laranja-avermelhada a rosada, isabelina ou ocrácea, tomentosa a glabra, geralmente zonada. Superfície himenial poróide, concolor à superfície superior, cinza a quase preta quando desidratada em algumas espécies, poros relativamente pequenos a muito pequenos. Contexto homogêneo, branco, amarelado, alaranjado ou castanho-claro. Sistema hifálico monomítico, às vezes aparentemente dimítico, hifas generativas não amilóides e não dextrinóides, com septos simples, largura e espessura da parede variáveis, em algumas espécies parede espessa a sólidas, sem septos (lembrando hifas esqueléticas). Cistídios ausentes ou presentes, hialinos, claviformes, parede incrustada a lisa; cistidíolos presentes em muitas espécies e entre os basídios, ventricososapiculados, parede fina e lisa. Basidiósporos ovóides a globosos, hialinos, não amilóides e não dextrinóides, parede fina e lisa, normalmente pequenos.

Rigidoporus apresenta distribuição cosmopolita, mas a maioria das espécies ocorre em regiões tropicais. 
Ryvarden \& Iturriaga (2003) apresentaram uma chave paras espécies de distribuição neotropical. $\mathrm{O}$ gênero abrange espécies lignícolas e causadoras de podridão branca (Gugliotta \& Bononi 1999).

Foram identificados Rigidoporus lineatus (Pers.) Ryvarden, $R$. microporus (Sw.) Overeem e $R$. vinctus (Berk.) Ryvarden para o Parque.

Rigidoporus lineatus (Pers.) Ryvarden, Norw. Jl. Bot. 19: 236. 1972 = Polyporus lineatus Pers., Gaudichaud Bot. Frey. Voy. monde: 174. 1827.

Figuras 9-12

Basidioma lignícola, anual, efuso-reflexo a pileado, solitário a lateralmente conato, imbricado, muito rígido quando seco. Píleo flabeliforme a dimidiado, 0,3-3,5 × 0,6-9,5 cm, até $0,7 \mathrm{~cm}$ espesso na base. Superfície superior castanha a cremealaranjada, concentricamente zonada. Margem lobada a inteira, concolor à superfície superior, estéril, involuta quando seca. Superfície himenial poróide, castanho-alaranjada, ás vezes levemente rosada, poros circulares a alongados, 5-9/mm; tubos concolores à superfície himenial, até $5 \mathrm{~mm}$ compr. Contexto homogêneo, creme a concolor à superfície himenial, até $2 \mathrm{~mm}$ espesso. Sistema hifálico monomítico; hifas generativas hialinas, não amilóides e não dextrinóides, com septo simples, parede fina a espessa, 3,75-6,25 $\mu \mathrm{m}$ diâm. Cistídios presentes na trama, hialinos, com ápice incrustado, 7,5-18,75 $\mu \mathrm{m}$ diâm.; cistidíolos presentes, ventricosos, apiculados, hialinos, parede fina e lisa, 12-18,75 × 6-7,5 $\mu \mathrm{m}$. Basídios claviformes, hialinos, tetraesporados, 6-8,4 $\mu \mathrm{m}$ diâm. Basidiósporos globosos a subglobosos, hialinos, não amilóides e não dextrinóides, parede fina e lisa, 5(-6,25) $\mu \mathrm{m}$ diâm.

Material examinado: BRASIL. SÃo PAUlo: São Paulo, Parque Estadual das Fontes do Ipiranga, s.d., s.col. (SP141943); 1-II-1960, O. Fidalgo et al. s.n. (SP46766; SP46767); 8-II-1960, J.S. Furtado \& O. Fidalgo s.n. (SP47665); 22-XI-1960, E.F. Campos \& R. Salles s.n. (SP53624); 25-XI-1960, E.F. Campos s.n. (SP53763); 17-I-1969, B. Skvortzov s.n. (SP103627); 22-XII-1969, B. Skvortzov s.n. (SP107260); 26-XII-1969, B. Skvortzov s.n. (SP107273); 27-II-1970, B. Skvortzov s.n. (SP107473); 12-IV-1978, S.F.B. Trufem 108 (SP); 24-I-1987, L. Ryvarden et al. 319 (SP); 22-XII-1992, L.K. Okino \& R. Maziero s.n. (SP250938); 14-IX-1995, L.K. Okino s.n. (SP392801); 24-XI-1995, A.M. Gugliotta et al. 572 (SP); 19-XII-2002, M.
Capelari 4231 (SP); 26-III-2003, U.C. Peixoto s.n. (SP392803); 16-II-2004, C. Puccinelli et al. s.n. (SP308015); 8-II-2006, A.M. Gugliotta \& T.V.S. Campacci 1226 (SP).

Verificou-se que as exsicatas relacionadas por Bononi et al. (1981), como Rigidoporus microporus (SP103627), Fomes microporus (SP46766, SP46767, SP47665, SP53624 e SP53763) e R. lignosus (SP141943 e SP142110), pertencem à espécie $R$. lineatus, bem como as exsicatas, citadas nesse mesmo trabalho como Rigidoporus sp. (SP107260, SP10273 e SP107473).

A espécie é morfologicamente muito semelhante a Rigidopous microporus, da qual difere por apresentar cistídios incrustados, que ocorrem na trama, no final dos dissepimentos, principalmente próximo à base do basidioma, e basidiósporos que são maiores.

A espécie apresenta distribuição pantropical; no Brasil foi citada para os Estados de Alagoas (Gibertoni et al. 2004), Amapá (Sotão et al. 1991, 2003), Paraíba (Gibertoni et al. 2004), Paraná (Rajchenberg \& Meijer 1990, Meijer 2006), Pernambuco (Tavares 1939, como Polyporus zonalis Berk., Maia et al. 2002, Gibertoni et al. 2004), Rio Grande do Sul (Rick 1960, como P. zonalis, Silveira \& Guerrero 1989), Santa Catarina (Loguercio-Leite \& Wright 1991, Gonçalves \& Loguercio-Leite 2001) e São Paulo, onde é comum em áreas de Mata Atlântica (Gugliotta \& Bononi 1999). Sua ocorrência no Pefi já foi relatada por Jesus (1993). Para a sinonímia consultar Gilbertson \& Ryvarden (1987).

Rigidoporus microporus (Sw.) Overeem, Icon. Fung. Malay. 5: 1. 1924 =Boletus microporus Sw., Fl. Ind. Occid. 3: 1925. 1806.

Figuras 13-15

Basidioma lignícola, anual, efuso-reflexo a pileado, imbricado, muito rígido quando seco. Píleo flabeliforme a ungulado, 1,2-3,5 × 1,2-2,5 cm, até 0,4 $\mathrm{cm}$ espesso na base. Superfície superior castanha a creme-alaranjada, concentricamente zonada. Margem lobada a inteira, concolor à superfície superior, estéril, involuta quando seca. Superfície himenial poróide, castanho-alaranjada a avermelhada, poros circulares, $6-9 / \mathrm{mm}$; tubos concolores à superfície himenial, até $3 \mathrm{~mm}$ compr. Contexto homogêneo, creme, até $1 \mathrm{~mm}$ espesso. Sistema hifálico monomítico; hifas generativas hialinas, não amilóides e não dextrinóides, com septo simples, 
parede fina a espessa, 3,75-6,25 $\mu \mathrm{m}$ diâm. Cistídios ausentes; cistidíolos presentes, de difícil visualização, ventricosos, apiculados, hialinos, parede fina e lisa, 12,5-20 × 6,25-12,5 $\mu \mathrm{m}$. Basídios não observados. Basidiósporos globosos a subglobosos, hialinos, não amilóides e não dextrinóides, parede fina e lisa, 3,75-4,5 $\mu \mathrm{m}$ diâm.

Material examinado: BRASIL. SÃo PAULO: São Paulo, Parque Estadual das Fontes do Ipiranga, 15-II-1960, O. Fidalgo et al. s.n. (SP 47230); 18-II-1960, M.E.P.K. Fidalgo \& J.S. Furtado s.n. (SP47255); 1-XII-1960, E.F.Campos \& A. Morais s.n. (SP53723); 31-III-1986, M.A. Jesus s.n. (SP211929); 23-X-2001, A.M. Gugliotta et al. 1143 (SP); 3-X-2003, 17-II-2005, G.R. Leal \& D. Ferrari G3/05 (SP), 7-II-2007, A.M. Gugliotta et al. 1235 (SP).

Rigidoporus microporus é facilmente reconhecido pelo basidioma alaranjado a avermelhado, séssil a efuso-reflexo, muito rígido quando seco, porém pode ser confundido com $R$. lineatus, do qual se distingue pela ausência de cistídios.

A espécie apresenta distribuição pantropical (Ryvarden \& Johansen 1980) e no Brasil foi citada para os Estados de Alagoas (Gibertoni et al. 2004), Bahia (Góes Neto et al. 2003), Paraná (Meijer 2006), Paraíba (Gibertoni et al. 2004), Pernambuco (Maia et al. 2002, Gibertoni \& Cavalcanti 2003, Gibertoni et al. 2004), Rio Grande do Sul (Rick 1960, como Polyporus lignosus Klotzsch), Rondônia (Capelari \& Maziero 1988), Roraima (Jesus 1996) e São Paulo (Fidalgo \& Fidalgo 1957, como Fomes lignosus (Klotzsch) Lloyd, Gugliotta 1997, Gugliotta \& Bononi 1999). Sua ocorrência no PEFI já foi relatada por Bononi et al. (1981) e por Jesus (1993). Para a sinonímia consultar Ryvarden \& Johansen (1980).

Rigidoporus vinctus (Berk.) Ryvarden var. vinctus, Norw. Jl. Bot. 19: 143. 1972 = Polyporus vinctus Berk., Ann. Mag. nat. Hist., Sér. 2, 9: 196. 1852.

Figuras 16-19

Basidioma lignícola, ressupinado, anual, até 2 $\mathrm{mm}$ espesso. Margem estéril, esbranquiçada, até 2 $\mathrm{mm}$. Superfície himenial poróide, castanho-rosada, poros regulares e hexagonais, $7-10 / \mathrm{mm}$; tubos concolores à superfície himenial, até $1 \mathrm{~mm}$ compr. Contexto homogêneo, creme, até $1 \mathrm{~mm}$ espesso. Sistema hifálico monomítico, aparentemente dimítico; hifas generativas não-amilóides e nãodextrinóides, hialinas, com septo simples, parede fina a espessa, quase sólida, podendo ser confundida com hifas esqueléticas, raramente ramificadas, 3,75-8,75 $\mu \mathrm{m}$ diâm. Cistídios presentes, hialinos, fortemente incrustados, imersos ou projetando-se através do himênio, parede espessa, até $15 \mu \mathrm{m}$ diâm.; cistidíolos presentes, ventricosos a mamilados, hialinos, parede fina e lisa, 12,5-27,5 × 7,5-10 $\mu \mathrm{m}$. Basídios não observados. Basidiósporos globosos a subglobosos, hialinos, parede fina e lisa, não amilóides e não dextrinóides, 3,75-5 $\mu \mathrm{m}$ diâm.

Material examinado: BRASIL. SÃo PAULO: São Paulo, Parque Estadual das Fontes do Ipiranga, 24-I-1987, L. Ryvarden et al. 24328 (SP), 19-XII-2002, M. Capelari 4232 (SP).

Rigidoporus vinctus (Berk.) Ryvarden var. cinereus (Bres.) Setliff, Mycologia 64: 695. $1972 \equiv$ Poria carneopallens f. cinerea Bres., Bull., Soc. mycol. Fr. 6: 46.1890

Apresenta as mesmas características que Rigidoporus vinctus var. vinctus, diferindo pelo basidioma perene, com até três camadas, 1-2 mm espessa cada camada e superfície himenial castanho-rosada quando fresca, tornando-se castanho-acinzentada quando seca.

Material examinado: BRASIL. São PAUlo: São Paulo, Parque Estadual das Fontes do Ipiranga, 24-I-1987, L. Ryvarden et al. 24310 (SP).

Rigidoporus vinctus difere das demais espécies de Rigidoporus do PEFI pelo basidioma ressupinado, que pode ser anual (var. vinctus) a perene (var. cinereus). Segundo Nuñez \& Ryvarden (2001), a espécie apresenta hifas gloepleurais na trama que podem estar ausentes em alguns espécimes; tais hifas não foram observadas nos espécimes do Parque.

A espécie apresenta ampla distribuição em regiões tropicais e em regiões mais quentes da zona temperada (Ryvarden \& Johansen 1980, Gilbertson \& Ryvarden 1987) e no Brasil foi citada para os Estados do Paraná (Ryvarden \& Meijer 2002, Meijer 2006), Pernambuco (Gibertoni et al. 2004) e Santa Catarina (Loguercio-Leite \& Wright 1991, como Junghuhnia vincta (Berk.) Hood \& E.A. Dick). A ocorrência de Rigidoporus vinctus var. vinctus no Estado do Amazonas foi relatada por Setliff (1972). As duas variedades ocorrem no Estado de São Paulo (Gugliotta \& Bononi 1999). Sua ocorrência no PEFI consta do trabalho de Jesus (1993). Para a sinonímia consultar Setliff (1972). 

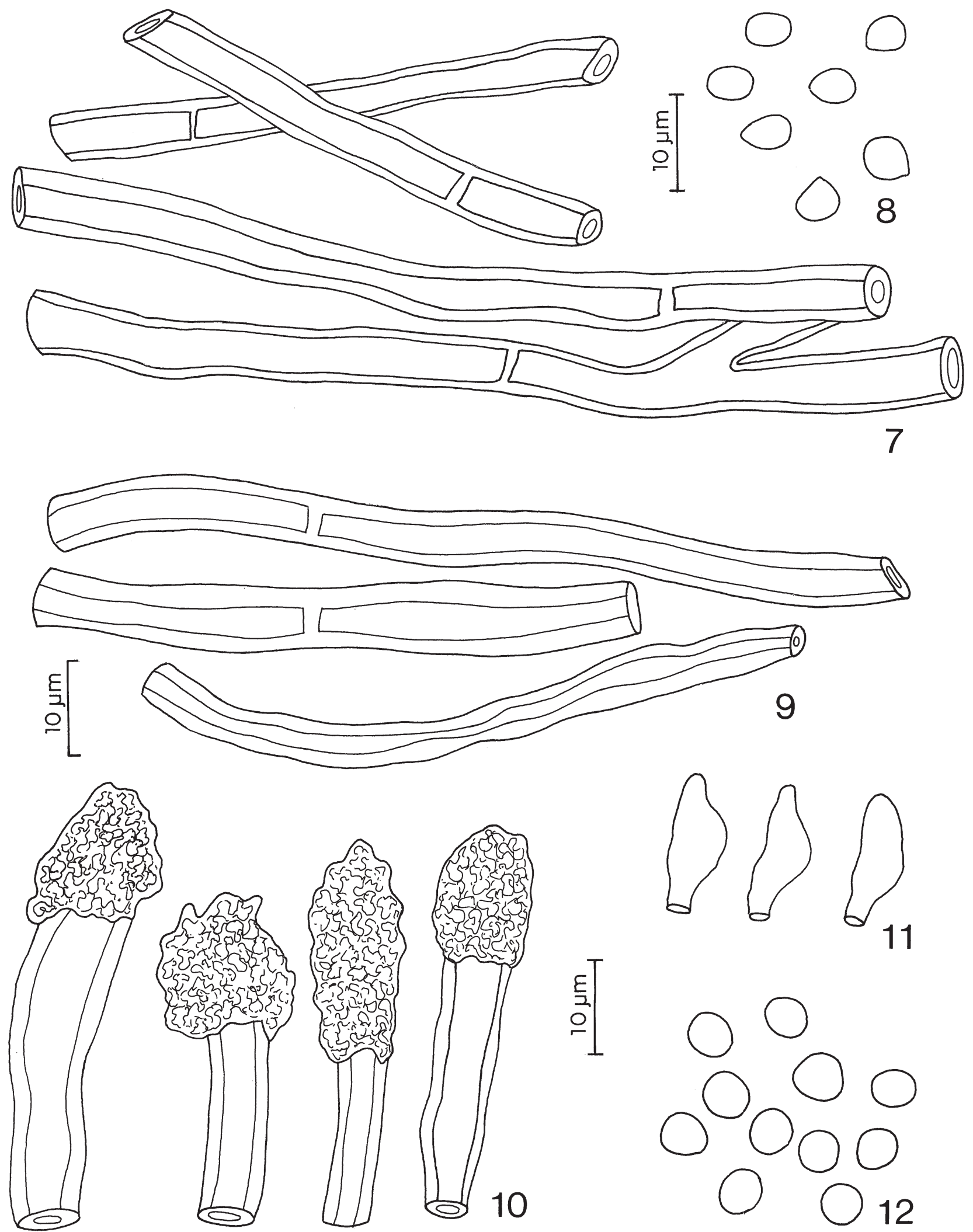

Figuras 7-8. Hydnopolyporus fimbriatus. 7. Hifas generativas. 8. Basidiósporos. Figuras 9-12. Rigidoporus lineatus. 9. Hifas generativas. 10. Cistídios. 11. Cistidíolos. 12. Basidiósporos. 

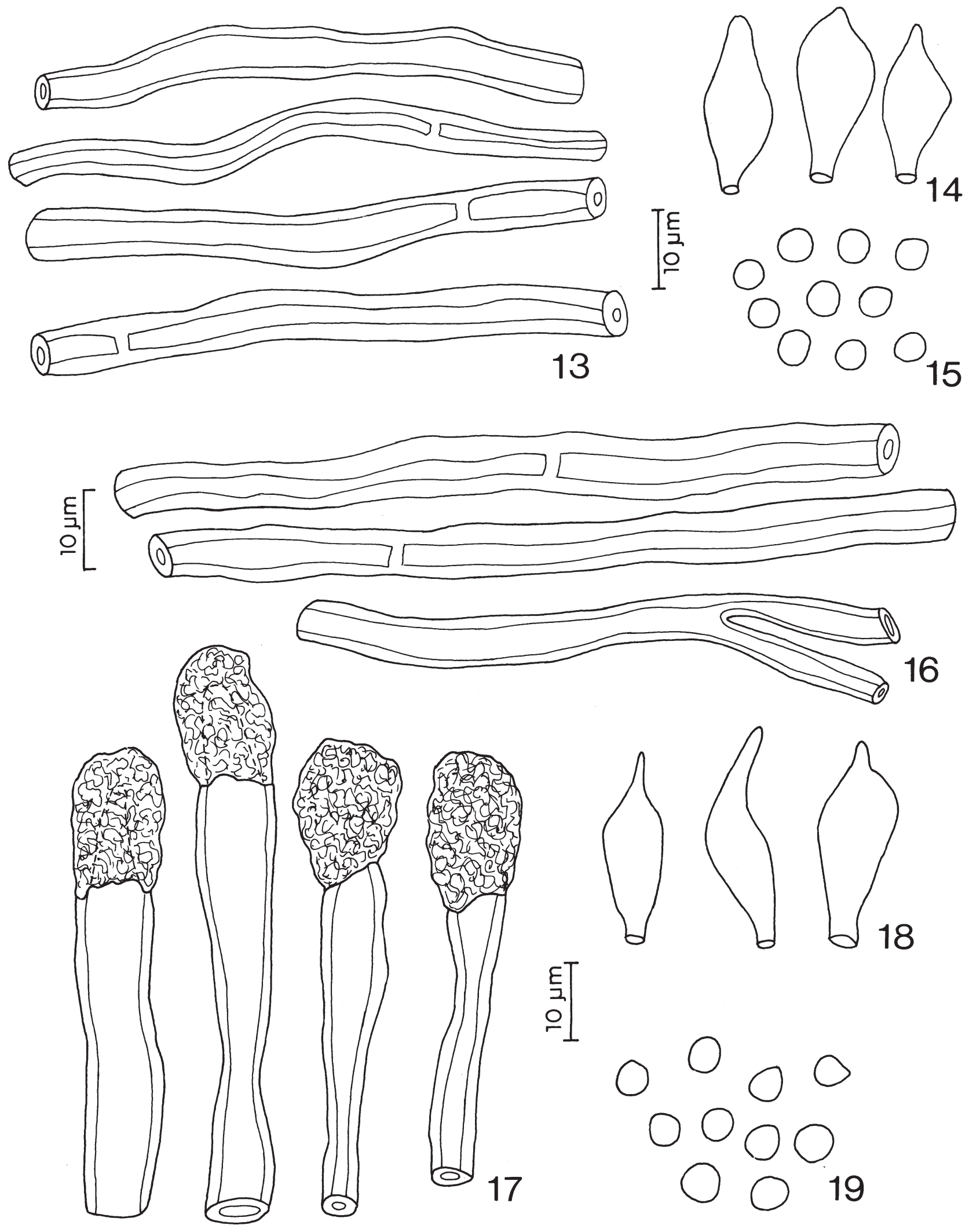

Figuras 13-15. Rigidoporus microporus. 13. Hifas generativas. 14. Cistidíolos. 15. Basidiósporos. Figuras 16-19. Rigidoporus vinctus var. vinctus. 16. Hifas generativas. 17. Cistídios. 18. Cistidíolos. 19. Basidiósporos. 


\section{Agradecimentos}

As autoras agradecem ao $\mathrm{CNPq}$, pela bolsa de iniciação científica dentro do programa PIBIC concedida à primeira autora; à FAPESP pelo apoio financeiro (processo 04/04310-2) e à Maria Cecília Tomasi pela cobertura à nanquim, das ilustrações.

\section{Literatura citada}

Almeida Filho, O.M., Bueno, R. \& Bononi, V.L.R. 1993. Algumas espécies de fungos basidiomicetos dos manguezais do Estado de São Paulo. Hoehnea 20: 87-92.

Bicudo, D.C., Forti, M.C. \& Bicudo, C.E.M. 2002. Parque Estadual das Fontes do Ipiranga (PEFI): unidade de conservação que resiste à urbanização de São Paulo. Secretaria do Meio Ambiente, São Paulo.

Bononi, V.L.R. 1979. Basidiomicetos do Parque Estadual da Ilha do Cardoso: I. Espécies hidnóides. Rickia 8: 63-74.

Bononi, V.L.R. 1984. Basidiomicetos do cerrado da Reserva Biológica de Moji-Guaçu, SP. Rickia 11: $1-25$.

Bononi, V.L.R., Trufem, S.F.B. \& Grandi, R.A.P. 1981. Fungos macroscópicos do Parque Estadual das Fontes do Ipiranga, depositados no Herbário do Instituto de Botânica. Rickia 9: 37-53.

Capelari, M. \& Maziero, R. 1988. Fungos macroscópicos do Estado de Rondônia, Região dos Rios Jaru e JiParaná. Hoehnea 15: 28-36.

Fidalgo, O. 1963. Studies on the type species of the genus Hydnopolyporus Reid. Mycologia 55: 713-727.

Fidalgo, O. 1968. As microestruturas e sua importância na sistemática dos fungos superiores. Rickia 3: 117-159.

Fidalgo, O. 1969. Revision of the genus Heteroporus Láz. emend. Donk. Rickia 4: 99-208.

Fidalgo, O. \& Bononi, V.L.R. (coords.). 1984. Técnicas de coleta, preservação e herborização de material botânico. Instituto de Botânica, São Paulo.

Fidalgo, O. \& Fidalgo, M.E.P.K. 1957. Revisão de Fungi São Paulensis. Arquivos do Museu Nacional 43: 157-188.

Fidalgo, O., Fidalgo, M.E.P.K. \& Furtado, J.S. 1965. Fungi of the "cerrado" region of São Paulo. Rickia 2: 55-71.

Gerber, A.L. \& Loguercio-Leite, C. 2000. Polyporoid wood-rotting fungi (Basidiomycetes) II - new records from Southern Brazil. Mycotaxon 76: 175-185.

Gibertoni, T.B.\& Cavalcanti, M.A.Q. 2003. A mycological survey of the Aphyllophorales (Basidiomycotina) of the Atlantic Rain Forest in the State of Pernambuco, Brazil. Mycotaxon 87: 203-211.
Gibertoni, T.B., Ryvarden, L. \& Cavalcanti, M.A.Q. 2004. Poroid fungi (Basidiomycota) of the Atlantic Rain Forest in Northeast Brazil. Synopsis Fungorum 18: 33-43.

Gilbertson, R.L. \& Ryvarden, L. 1986. North American Polypores. Fungiflora, Oslo.

Gilbertson, R.L. \& Ryvarden, L. 1987. North American Polypores. Fungiflora, Oslo.

Góes Neto, A. 1999. Polypore diversity in the State of Bahia, Brazil: a historical review. Mycotaxon 72: 43-56.

Góes Neto, A., Marques, M.F.O., Andrade, J.D. \& Santos, D.S. 2003. Lignicolous aphyllophoroid Basidiomycota in an Atlantic Forest fragment in the semi-arid Caatinga region of Brazil. Mycotaxon 88: 359-364.

Gonçalves, G.V.C. \& Loguercio-Leite, C. 2001. Biodiversidade de fungos poróides xilófilos (Basidiomycetes), na Unidade de Conservação Ambiental Desterro (UCAD), Ilha de Santa Catarina, SC, Brasil. Insula 30: 1-19.

Guerrero, R.T. \& Homrich, M.H. 1983. Fungos macroscópicos comuns no Rio Grande do Sul. Editora da Universidade Federal do Rio Grande do Sul, Porto Alegre.

Gugliotta, A.M. 1997. Polyporaceae de mata ciliar da Estação Experimental e Reserva Biológica de MojiGuaçu, SP, Brasil. Hoehnea 24: 89-106.

Gugliotta, A.M. \& Bononi, V.L.R. 1999. Polyporaceae do Parque Estadual da Ilha do Cardoso, São Paulo, Brasil. Boletim do Instituto de Botânica 12: 1-112.

Jesus, M.A. 1993. Basidiomicetos lignocelulolíticos de floresta nativa e de Pinus elliottii Engelm. do Parque Estadual das Fontes do Ipiranga, São Paulo, SP. Hoehnea 20: 119-126.

Jesus, M.A. 1996. Contribution to the knowledge of woodrotting fungi in Brazil II. Checklist of fungi from Maracá Island, Roraima State. Mycotaxon 57: 323-328.

Kirk, P.M., Cannon, P.F., David, J.C. \& Stalpers, J.A. 2001. Ainsworth \& Bisby's Dictionary of Fungi. 9th ed. CAB International, Wallingford.

Loguercio-Leite, C. \& Wright J.E. 1991. Contribution to a biogeographical study of the Austro-american xylophilous polypores (Aphyllophorales) from Santa Catarina Island, SC, Brazil. Mycotaxon 41: 161-166.

Maia, L.C., Yano-Melo, A.M. \& Cavalcanti, M.A.Q. 2002. Diversidade de Fungos no Estado de Pernambuco. In: M. Tabarelli \& J.M.C. Silva (orgs.). Diagnóstico da Biodiversidade de Pernambuco. Secretaria de Ciência, Tecnologia e Meio Ambiente e Editora Massangana, Recife, pp. 15-50.

Meijer, A.A.R. 2006. Preliminary list of macromycetes from the Brazilian State of Paraná. Boletim do Museu Botânico Municipal 68: 1-55. 
Nuñez, M. \& Ryvarden, L. 2001. East Asian Polypores. Fungiflora, Oslo.

Rajchenberg, M. \& Meijer, A.A.R. 1990. Note and noteworthy polypores from Paraná and São Paulo States, Brazil. Mycotaxon 38: 173-185.

Rayner, A.D.M. 1995. Fungi, a vital component of ecosystem function in Woodland. In: D. Allsopp, R.R. Colwell \& D.L. Howksworth (eds.). Microbial Diversity and Ecosystem Function. CAB International, Cambridge, pp. 231-251.

Reid, D.A. 1962. Notes on fungi which have been referred to the Thelephoraceae sensu lato. Persoonia 2: $109-170$.

Rick, J. 1960. Basidiomycetes Eubasisii in Rio Grande do Sul, Brasília 4. Meruliaceae, Polyporaceae, Boletaceae. Iheringia, série Botânica 7: 193-295.

Ryvarden, L. 1991. Genera of Polypores: nomenclature and taxonomy. Fungiflora, Oslo.

Ryvarden, L. \& Gilbertson, R.L. 1993. European Polypores. Fungiflora, Oslo.

Ryvarden, L. \& Iturriaga, T. 2003. Studies in neotropical polypores 10. New polypores from Venezuela. Mycologia 95: 1066-1077.

Ryvarden, L. \& Johansen, I. 1980. A preliminary flora of East Africa. Fungiflora, Oslo.

Ryvarden, L. \& Meijer, A.A.R. 2002. Studies in neotropical polypores 14. New species from the State of Paraná, Brazil. Synopsis Fungorum 15: 34-69.
Setliff, E.C. 1972. The taxonomy and morphology of Poria vincta. Mycologia 64: 689-701.

Silveira, R.M.B. \& Guerrero, R.T. 1989. Os gêneros Rigidoporus Murr. e Flaviporus Murr. (Basidiomycetes) do Parque Nacional de Aparados da Serra, RS. Acta Botanica Brasilica (supl.) 3: 29-45.

Silveira, R.M.B. \& Guerrero, R.T. 1991. Aphyllophorales poliporóides (Basidiomycetes) do Parque Nacional de Aparados da Serra, Rio Grande do Sul. Boletim do Instituto de Biociências 48: 1-127.

Sotão, H.M.P., Bononi, V.L.R. \& Figueiredo, T.S. 1991. Basidiomycetes de manguezais da Ilha de Maracá, Amapá, Brasil. Boletim do Museu Paraense Emílio Goeldi, série Botânica 7: 109-114.

Sotão, H.M.P., Campos, E.L., Gugliotta, A.M. \& Costa, S.P.S.E. 2003. Fungos Macroscópicos: Basidiomycetes. In: M.E.B. Fernandes (org.). Os manguezais da costa norte brasileira. Fundação Rio Bacanga, São Luís, pp. 45-59.

Tavares, I. 1939. Catálogo dos fungos de Pernambuco. Boletim da Secretaria de Agricultura, Indústria e Comércio do Estado de Pernambuco 4: 1-33.

Teixeira, A.R. 1962. As microestruturas do basidiocarpo e sistemática do gênero Fomes (Fries) Kickx. Rickia 1: 13-93.

Teixeira, A.R. 1995. Método para estudo das hifas do basidiocarpo de fungos poliporáceos. Instituto de Botânica, São Paulo. 